\title{
Probabilistic assessment of industrial heritage structures: framework and case study
}

\author{
M. Sykora \& M. Holicky \\ Klokner Institute, Czech Technical University in Prague, Czech Republic
}

\begin{abstract}
At present, considerable effort is aimed at the re-use of industrial heritage structures in order to preserve their heritage value and avoid wasting energy. Such structures do not often fulfil requirements of present codes of practice. Decisions about construction interventions should be based on the complex assessment of the structure considering actual material properties, environmental influences and satisfactory past performance. Simplified conservative procedures of structural design given in present codes may lead to expensive repairs and losses of the heritage value. The probabilistic procedure is thus accepted to enhance reliability assessment. Application is illustrated by a case study concerning a former factory for boiler production. Two fundamental procedures of probabilistic updating are described: (1) updating of the distribution of iron strength using non-destructive and destructive tests, and (2) direct updating of failure probability considering satisfactory past performance of the structure. It appears that the probabilistic assessment may prevent expensive repairs.

Keywords: industrial heritage, reliability assessment, probabilistic methods.
\end{abstract}

\section{Introduction}

A number of factories, warehouses, power plants and other industrial buildings have been registered worldwide as industrial cultural heritage. Such structures are mostly of significant architectural, historic, technological or social value [1]. Protection (including adaptations and re-use) of these structures is an important issue, positively contributing to the sustainable development of urban areas by:

- Preservation of cultural values - the heritage value of the structure commonly originates from its uniqueness, quality of craft execution, 
relationship with an important event or person, urban context, importance as a landmark etc.,

- Recycling of potential resources and avoiding wasting energy,

- Facilitating the economic regeneration of regions in decline.

However, insufficient attention seems to be paid to systematic recognizing, declaring and protecting the industrial heritage in most countries. This is an alarming situation as the lack of attention and awareness of the industrial structures may gradually lead to their extinction.

When out of use the industrial heritage buildings are degrading and often turning into ruins. Re-use and adaptation to hotels, museums, residential parks, commercial centres etc. help protect cities' cultural heritage [2].

The protection of the industrial heritage is a multidisciplinary topic including historical, architectonic, civil engineering and ecological aspects. In 1978 the International Committee on the Conservation of the Industrial Heritage (TICCIH) was founded to study, protect, conserve and explain remains of industrialisation. In the Czech Republic numerous industrial heritage structures were built from 1870 to 1930 . Platform coordinating views of architects and civil engineers on protection of the industrial heritage is provided by the Research Centre for Industrial Heritage. The Centre maintains a database of the Czech industrial monuments (containing more then 10000 monuments) and seeks for new uses of the industrial heritage structures. At present several research projects focused on the industrial heritage are supported by the Ministry of Culture of the Czech Republic.

It has been recognised that many heritage structures do not fulfil requirements of present codes of practice. Decisions about adequate construction interventions should be based on the complex assessment of a structure. Minimisation of construction interventions is required in rehabilitation and upgrades, but sufficient reliability should also be guaranteed. Application of simplified procedures used for design of new structures may lead to expensive repairs and losses of the heritage value. In the paper a general probabilistic procedure is thus proposed to improve the reliability assessment of industrial heritage buildings particularly with respect to:

- Better description of uncertainties related to the assessment and

- Facilitating inclusion of results of inspections and tests and the satisfactory past performance of a structure.

Moreover, outcomes of the probabilistic assessment can be utilised in a riskbased decision concerning safety measures [3].

\section{General aspects of assessment}

As a rule, the re-use and adaptation of industrial structures requires assessment of structural reliability. However, it appears that insufficient attention has been paid by experts to specific issues of the reliability assessment of such structures 
so far. The following differences between the assessment and design of new structures should be carefully considered:

- Social and cultural aspects - loss of heritage values,

- Economic aspects - additional costs of measures to enhance reliability of a heritage building in comparison with a new structure (at a design stage cost of such measures is much lower than the cost of strengthening),

- Principles of the sustainable development - waste reduction and recycling of materials (these aspects may be more significant in case of the assessment),

- Lack of information for the assessment - limited number of tests restricted by protection of the heritage value, even though very important due to variability of mechanical properties and changes that may have occurred during the working life of a structure (including effect of deterioration and damage).

Significant uncertainties related to actual material properties and structural conditions usually need to be considered in the reliability assessment. In design codes a limited number of safety factors are intended to cover all possible design situations. Therefore, verifications based on deterministic design procedures may be too conservative. Application of commonly used design procedures may thus lead to expensive repairs and losses of the heritage value. It follows that use of deterministic design procedures may not be an appropriate approach.

It has been recognised that assessment of existing structures is a structurespecific task that is difficult to codify. In accordance with EN 1990 [4] and ISO 13822 [5] a general probabilistic procedure is thus accepted here to enhance the reliability assessment of the industrial heritage buildings. The procedure facilitates inclusion of results of inspections, testing and consideration of the satisfactory past performance.

\section{Principles of probabilistic analysis}

Probabilistic methods may be useful for the assessment of existing structures where appropriate data can be obtained $[3,6]$. Uncertainties that can be greater than in structural design (such as statistical uncertainty due to a limited amount of test data or uncertainties related to inaccessible members and connections where construction details cannot be inspected and verified) can be adequately described by such methods [7]. On the contrary, some of the uncertainties reflected (often implicitly) in the load and resistance factors (modelling approximations, deviations from specified dimensions and strengths) may be less than in new construction, particularly when in-situ measurements are taken. 


\subsection{Specification of models for basic variables}

Models for basic variables should be adjusted to the actual situation and state of a structure and verified by inspection and testing. The following principles should be taken into account:

- Material properties should be considered according to the actual state of a structure verified by destructive or non-destructive testing. It may often be appropriate to combine limited new information with prior information. Bayesian techniques provide a consistent basis for this updating; details are provided e.g. in ISO 12491 [8] or in materials of the Joint Committee on Structural Safety JCSS [3, 9]. Prior information may be found in normative documents (for example in the Czech National Annex to ISO 13822 [5] where characteristics of different historical materials are provided), scientific literature, reports of producers etc.

- When significant deterioration is observed, an appropriate deterioration model should be used to predict changes in structural parameters due to foreseen environmental conditions, structural loading, maintenance practices and past exposures, based on theoretical or experimental investigation, inspection and experience.

- Dimensions of structural members should be determined by measurements. When the original design documentation is available and no changes in dimensions exist, nominal dimensions given in the documentation may be used.

- Load characteristics should be introduced considering the values corresponding to the actual situation. For structures with significant permanent actions, the actual geometry should be verified by measurements and weight densities should be obtained from tests.

- Model uncertainties should be considered in the same way as at a design stage unless previous structural behaviour (especially damage) indicates otherwise. In some cases model factors, coefficients and other design assumptions may be established from measurements.

It follows that reliability verification of a heritage building should be backed up by inspection including collection of appropriate data. Evaluation of prior information and its updating using newly obtained measurements may be a crucial step of the assessment.

\subsection{Probabilistic updating}

The failure probability, related to the period from the assessment to the end of a working life $t_{\mathrm{D}}$, can be obtained from a general probabilistic relationship:

$$
p_{\mathrm{f}}\left(t_{\mathrm{D}}\right)=\mathrm{P}\left\{\min \mathrm{Z}[\mathbf{X}(\tau)]<0 \text { for } 0<\tau<t_{\mathrm{D}}\right\}=\mathrm{P}\left\{F\left(t_{\mathrm{D}}\right)\right\}
$$


where $\mathrm{Z}(\cdot)=$ limit state function; $\mathbf{X}(\cdot)=$ vector of basic variables including model uncertainties, resistance, permanent and variable actions; and $F\left(t_{\mathrm{D}}\right)=$ failure in the interval $\left(0, t_{\mathrm{D}}\right)$.

When additional new information $I$ related to structural conditions is available, the failure probability may be updated according to [5] as follows:

$$
p_{\mathrm{f}}{ }^{\prime}\left(t_{\mathrm{D}} \mid I\right)=\mathrm{P}\left\{F\left(t_{\mathrm{D}}\right) \cap I\right\} / \mathrm{P}(I)
$$

The information should be selected to maximise correlation between the events $\{F\}$ and $\{I\}$. Strong correlation improves the posterior estimate of failure probability while weak correlation yields nearly the same estimates as based on Eq. (1) [7]. The new information may be based on:

(1) Inspections that can for instance provide data for the updating of a deterioration model,

(2) Material tests and in-situ measurements that can be taken to improve models of material or geometry properties,

(3) Consideration of the satisfactory past performance,

(4) Intensity of proof loading,

(5) Static and dynamic response to controlled loading.

In the first two cases the new information is usually applied in the direct updating of (prior) distributions of relevant basic variables that are commonly based on experience from assessments of similar structures, long-term material production, findings reported in literature or engineering judgement. The third case may be very important for the industrial heritage buildings and is described in details below. The fourth case is substantially similar to the third one. In the fifth case known structural response to controlled loading can lead to reduction of resistance model uncertainties.

Note that it can be important to consider the satisfactory past performance (the third case) for instance for a structure originally used as a factory that is to be used as a museum or gallery. Such a structure may have resisted to loads much greater than those expected for a future use.

The satisfactory past performance of a structure during a period $t_{\mathrm{A}}$ till the time of assessment may be included in the reliability analysis considering the conditional failure probability $p_{\mathrm{f}}$ (" $\left.t_{\mathrm{D}} \mid t_{\mathrm{A}}\right)$ that a structure will fail during a working life $t_{\mathrm{D}}$ given that it has survived the period $t_{\mathrm{A}}$. This probability may be estimated in several ways. When the load to which the structure has been exposed during the period $t_{\mathrm{A}}$ is known with negligible uncertainties, the resistance or a joint distribution of time-invariant variables may be truncated (a lower bound is set to the value of load). Using the bounded distribution, the conditional (updated) probability $p_{\mathrm{f}}^{\prime \prime}\left(t_{\mathrm{D}} \mid t_{\mathrm{A}}\right)$ can be estimated. This approach, similar to the updating for proof load testing [3], is illustrated elsewhere [10]. More generally, the updated failure probability may be determined using the following relationship:

$$
p_{\mathrm{f}} "\left(t_{\mathrm{D}} \mid t_{\mathrm{A}}\right)=\mathrm{P}\left\{F\left(t_{\mathrm{D}}\right) \cap \bar{F}\left(t_{\mathrm{A}}\right)\right\} / \mathrm{P}\left\{\bar{F}\left(t_{\mathrm{A}}\right)\right\}
$$


where $\bar{F}=$ complementary event to the failure. The updated probability can be determined by standard techniques for reliability analysis such as the FORM/SORM methods or importance sampling (see the case study below).

Reliability verification can be based on either of the following (equivalent) relationships:

$$
p_{\mathrm{f}}{ }^{\prime \prime}\left(t_{\mathrm{D}} \mid I\right)<p_{\mathrm{t}}, \quad \beta^{\prime \prime}\left(t_{\mathrm{D}} \mid I\right)=-\Phi^{-1}\left[p_{\mathrm{f}}{ }^{\prime \prime}\left(t_{\mathrm{D}} \mid I\right)\right] \geq \beta_{\mathrm{t}}
$$

where $p_{\mathrm{t}}=$ target failure probability; $\Phi^{-1}=$ inverse cumulative distribution function of the standardised normal variable; and $\beta_{\mathrm{t}}=$ target reliability index.

The target reliability level used for verification can be taken as the level of reliability implied by acceptance criteria defined in design codes. The target reliability level can also be established accounting for the required performance level for the structure, the reference period and possible failure consequences. In accordance with ISO 2394 [11], the performance requirements for existing structures are the same as for a new structure. Lower reliability targets for existing structures can be used if justified on the basis of economical, social and sustainable considerations [12, 13]; effect of a heritage value on the target reliability is discussed in $[14,15]$. For industrial heritage buildings $\beta_{\mathrm{t}}=3.1$ was accepted in [15] and is considered also in the presented study.

\section{Case study}

The proposed procedure is applied in a case study of the reliability assessment of a former factory for boiler production built in 1900s (Figure 1). A reconversion is conducted to adjust the building for use as headquarters of a publishing house. An anticipated working life is 50 years.

Characteristics of the resistance and permanent action are specified considering results of on-site surveys and original design documentation. Effects of degradation are negligible. Deterministic assessment reveals that the critical structural member is an iron truss girder supporting the roof (Figure 1). Suction due to wind pressure, causing buckling of a long-span lower chord of the girder, was identified as the most unfavourable load case; axial and shear forces need not to be taken into account. The following analysis is considerably simplified to illustrate key steps of the probabilistic updating rather than to describe casespecific details. The purpose of the case study is two-fold:

(1) To show development of the probabilistic model for iron strength using non-destructive and destructive tests,

(2) To illustrate consideration of the satisfactory past performance.

\subsection{Updating of the strength of iron}

Dissimilar to present construction materials, prior information (Section 3.1) for historic materials may not be available. For instance iron strengths vary in a wide range depending on a production process and producers. 


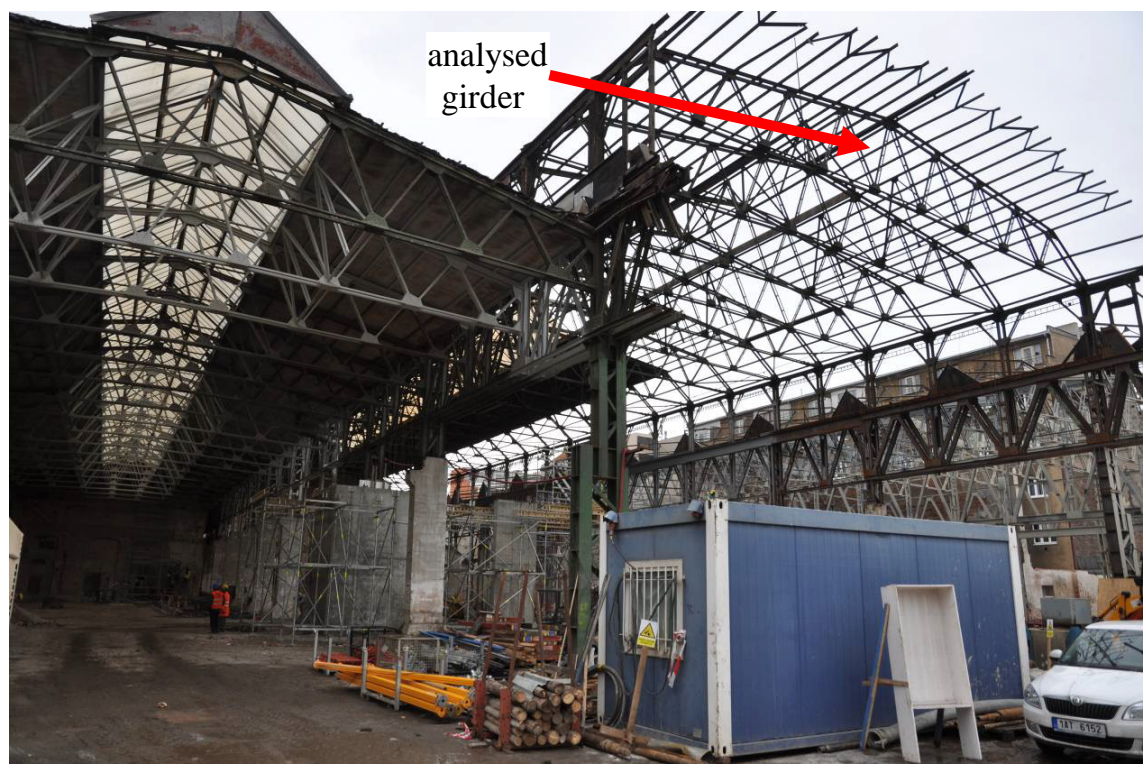

Figure 1: $\quad$ Former factory for boiler production in Prague - Karlin under reconversion.

That is why models for properties of historic materials need to be solely based on measurements and standard Bayesian updating (combining prior information with test results) $[3,10]$ can hardly be performed. However, the technique of the Bayesian updating can be efficiently applied when combining results of nondestructive (affected by a measurement error) and destructive (deemed to be associated with negligible measurement error) testing.

In the beginning of the analysis Brinell hardness tests were performed at ten locations of the structure. Using a conversion factor based on long-term experience with the test method, point estimates of the sample characteristics are obtained by the Method of moments [16]:

$$
m_{0}{ }^{\prime}=385 \mathrm{MPa}, s_{0}{ }^{\prime}=20.5 \mathrm{MPa}, n^{\prime}=10, v^{\prime}=n-1
$$

where $m_{0}{ }^{\prime}=$ mean, $s_{0}{ }^{\prime}=$ standard deviation, $n^{\prime}=$ sample size, $v^{\prime}=$ number of degrees of freedom for the standard deviation. Assuming a normal distribution of the iron strength $f$, the probability density function based on the ten measurements (following t-distribution [16]) is plotted in Figure 2. If a lognormal distribution is more appropriate, the variable is to be transformed to a normal variable [17].

Long-term experience with the Brinell method indicates a particular measurement $f_{0 i}$ ' be affected by an unbiased measurement error $\varepsilon$ (mean $\mu_{\varepsilon}=1$ ) with a standard deviation $\sigma_{\varepsilon}=0.15$. 


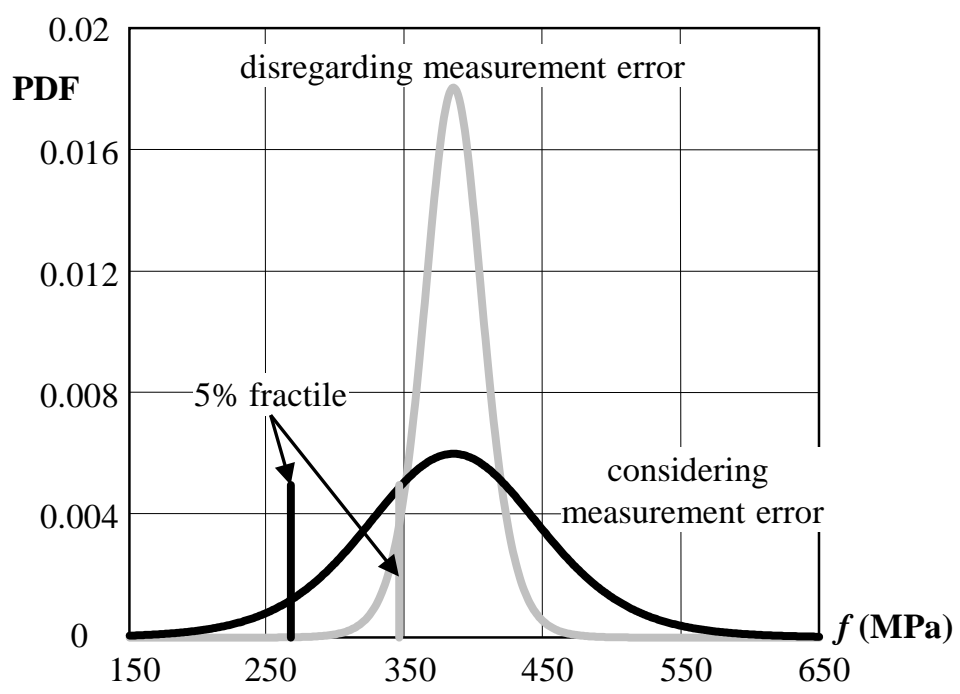

Figure 2: $\quad$ Probability density function of $f$ based on results of the Brinell tests.

An actual (true) value of the strength is estimated as the product of a test result and measurement error, $f_{i}{ }^{\prime}=\varepsilon f_{0 i}$ '. To account for $\varepsilon$ the sample characteristics are modified as follows [17]:

$m^{\prime} \approx \mu_{\varepsilon} m_{0}{ }^{\prime}=385 \mathrm{MPa} ; s^{\prime} \approx m^{\prime} \sqrt{ }\left[V_{\varepsilon}^{2}+V\left(m_{0}{ }^{\prime}\right)^{2}+V_{\varepsilon}^{2} V\left(m_{0}{ }^{\prime}\right)^{2}\right]=61.3 \mathrm{MPa}$

where $V_{\varepsilon}=\sigma_{\varepsilon} / \mu_{\varepsilon}$ is the coefficient of variation of the measurement error, and $V\left(m_{0}{ }^{\prime}\right) \approx s_{0}$ ' / $\left(m_{0}\right.$ ' $\left.\sqrt{ } n^{\prime}\right)$ is the coefficient of variation of the sample mean.

Apparently the measurement error significantly affects the sample standard deviation. This is also demonstrated in Figure 2 - the probability density function corresponds to a greater dispersion and 5\% fractile (commonly the characteristic value) considerably decreases. The effect on the design value is even more substantial.

To improve the material model, three samples were cut from members of the structure intended to be for replaced. Tensile strengths are as follows: $\mathbf{f}^{\mathrm{T}}=\{371$, 351, 418 (in MPa). The following sample characteristics are obtained:

$$
m=380 \mathrm{MPa}, s=34.4 \mathrm{MPa}, n=3, v=2
$$

According to ISO 12491 [8] the updated sample characteristics (combining prior information - non-destructive measurements here - and results from tensile tests) are: 


$$
\begin{array}{r}
n^{\prime \prime}=n^{\prime}+n=13 ; v^{\prime}=v^{\prime}+v+\delta\left(n^{\prime}\right)=12 ; m^{\prime \prime}=\left(n^{\prime} m^{\prime}+n m\right) / n^{\prime \prime}=384 \mathrm{MPa} \\
s^{\prime \prime}=\sqrt{ }\left\{\left[\left(v^{\prime}\left(s^{\prime}\right)^{2}+n^{\prime}\left(m^{\prime}\right)^{2}+v s^{2}+n m^{2}\right)-n^{\prime \prime}\left(m^{\prime \prime}\right)^{2}\right] / v^{\prime \prime}\right\}=55.0 \mathrm{MPa}
\end{array}
$$

where $\delta\left(n^{\prime}\right)=0$ for $n^{\prime}=0$ and $\delta\left(n^{\prime}\right)=1$ otherwise. The updated standard deviation is lower than that based on the Brinell method, however it is still considerably greater than the standard deviation obtained from tensile tests. It could be thus accepted to develop the model of $f$ using tensile tests only. However, the increase of the standard deviation due to measurement error is compensated by a considerable increase of the degrees of freedom ( $v=2$ and $v^{\prime \prime}=12$ ) that positively affects the left tail of the distribution. This is demonstrated in Figure 3 that shows the probability density functions of the iron strengths based on the Brinell method, results of tensile tests and updated distribution. The greatest estimate of $5 \%$ fractile is obtained for the updated distribution. Note that the difference becomes more significant for design values (commonly 1\%o fractiles).

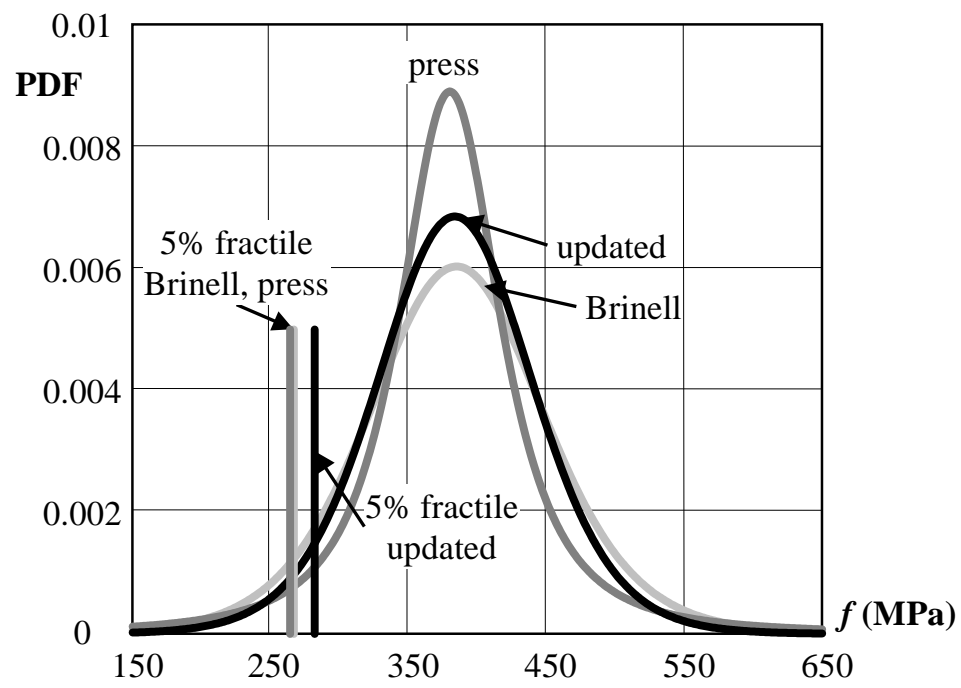

Figure 3: $\quad$ Probability density function of $f$.

Supplementary information on the updating of distributions can be found in $[3,9,16]$. It is emphasised that the proposed technique is not the only procedure to combine data affected by different uncertainties. An alternative procedure based on likelihood representation of uncertainties was proposed in [18].

\subsection{Updating of the failure probability}

Deterministic verification reveals that reliability of the girder is insufficient as the actual resistance is approximately by $20 \%$ lower than required by Eurocodes 
for new structures (considering the updated strength of iron). Probabilistic reliability analysis is based on the limit state function $\mathrm{Z}(\cdot)$ for the member exposed to buckling (notation and probabilistic models of the basic variables $\mathbf{X}$ is given in Table 1, following recommendations of JCSS [9]):

$$
\mathrm{Z}(\mathbf{X})=K_{R} \chi A f-K_{E}[G+W]
$$

where $\chi=$ buckling reduction factor, $A=$ cross-section area. Variability of the buckling reduction factor is covered by the uncertainty in model resistance; variability of the cross-section area based on in-situ measurements is negligible.

Table 1: $\quad$ Models for basic variables.

\begin{tabular}{|c|c|c|c|c|}
\hline Variable & Sym. & Distribution & $\mu_{X} / x_{\mathrm{k}}$ & $V_{X}$ \\
\hline Iron strength (updated) & $f$ & Lognormal & 1.36 & 0.14 \\
\hline Permanent load effect & $G$ & Normal & 1 & 0.05 \\
\hline Wind pressure (50-y. maxima) & $W$ & Gumbel & 0.7 & 0.35 \\
\hline Effect of the survived load & $S$ & Normal & 1.3 & 0.1 \\
\hline Resistance uncertainty & $K_{R}$ & Lognormal & 1 & 0.1 \\
\hline Load effect uncertainty & $K_{E}$ & Lognormal & 1 & 0.1 \\
\hline$x_{\mathrm{k}}=$ characteristic value
\end{tabular}

Using the FORM method and Eq. (1) the reliability index $\beta \approx 2.4$ is lower than the accepted target reliability level $\beta_{\mathrm{t}}=3.1$. The reliability is then updated considering the satisfactory past performance to improve this estimate. Available measurements from a neighbouring meteorological station reveal that in 2007 the structure was exposed to an extraordinary wind storm causing a wind pressure $S$ exceeding 1.3-times the characteristic value. Based on an expert judgement uncertainties in the survived load effect are described by a normal distribution with the mean equal to the observed value and coefficient of variation 0.1 . Given the survival of the load $S$, the updated reliability index $\beta^{\prime \prime}\left(t_{\mathrm{D}} \mid S\right) \approx 2.8$ follows from the conditional failure probability based on Eq. (3):

$$
\begin{gathered}
p_{\mathrm{f}}{ }^{\prime}\left(t_{\mathrm{D}} \mid S\right)=\mathrm{P}\left\{\left[K_{R} \chi A f-K_{E}(G+W)<0\right] \cap\left[K_{R} \chi A f-K_{E}(G+S)>0\right]\right\} / \\
/ \mathrm{P}\left\{K_{R} \chi A f-K_{E}(G+S)>0\right\}
\end{gathered}
$$

Note that the present conditions of the girder are assumed to be the same as those at the time of exposure to the load $S$. It is emphasised that information on previous loads should be always considered carefully and related to a relevant uncertainty.

The predicted reliability is still rather low. In general five options can now be considered:

(1) To improve information on variables significantly affecting structural reliability by inspections or tests;

(2) To upgrade the member; 
(3) To propose an adequate limit on the imposed action (irrelevant in the case of a roof girder, however);

(4) To accept a shorter remaining working (such as 15 years) and after that re-assess the girder;

(5) To derive optimum target reliability following the principles provided by ISO 2394 [11].

When the fourth option is accepted the updated reliability index $\beta$ " $(15 \mathrm{y} . \mid S) \approx$ 3.1 is obtained from Eq. (10) using 15-year maxima of the wind pressure. The fifth option is thoroughly discussed in $[12,13]$ as already mentioned earlier.

\section{Concluding remarks}

Reliability verifications of the industrial heritage buildings should be backed up by inspection including collection of appropriate data. Assessments based on simplified conservative procedures used for structural design may lead to expensive repairs and losses of the heritage value. Probabilistic methods can thus better describe uncertainties and take into account results of inspections and tests as well as satisfactory past performance. Numerical example reveals that it may be important to consider measurement errors related to non-destructive techniques. Direct updating of the failure probability can be effectively performed by the FORM/SORM methods and may improve reliability assessment.

\section{Acknowledgements}

This study is an outcome of the research project NAKI DF12P01OVV040 "Assessment of safety and working life of industrial heritage buildings", supported by the Ministry of Culture of the Czech Republic.

\section{References}

[1] TICCIH, The Nizhny Tagil Charter for the Industrial Heritage, The International Committee for the Conservation of the Industrial Heritage: Nizhny Tagil, pp. 6, 2003.

[2] Läuferts, M. and Mavunganidze, J., Ruins of the past: Industrial heritage in Johannesburg. Proc. STREMAH XI, eds. C.A. Brebbia, WIT Press: Ashurst Lodge, pp. 533-542, 2009.

[3] Diamantidis, D., Probabilistic Assessment of Existing Structures, Joint Committee on Structural Safety, RILEM Publications S.A.R.L.: 2001.

[4] EN 1990, Eurocode - Basis of structural design, CEN: Brussels, pp. 87, 2002.

[5] ISO 13822, Bases for design of structures - Assessment of existing structures, ISO TC98/SC2: Geneve, Switzerland, pp. 44, 2010. 
[6] Holicky, M. and Sykora, M., Structural assessment of heritage buildings. Proc. $1^{\text {st }}$ Int. Conf. Defence Sites: Heritage and Future 2012, eds. C. Clark and C.A. Brebbia, WIT Press: Ashurst Lodge (UK), pp. 69-80, 2012.

[7] Ellingwood, B.R., Reliability-based condition assessment and LRFD for existing structures. Structural Safety, 18(2-3), pp. 67-80, 1996.

[8] ISO 12491, Statistical methods for quality control of building materials and components, ISO: Geneve, Switzerland, pp. 30, 1997.

[9] JCSS, JCSS Probabilistic Model Code, Joint Committee on Structural Safety: Zurich, 2011.

[10] Sykora, M., Holicky, M. and Jung, K., Updating in the probabilistic assessment of existing structures. Transactions of the VSB - Technical University of Ostrava, Civil Engineering Series, XII(2), pp. 205-215, 2013.

[11] ISO 2394, General principles on reliability for structures, ISO: Geneve, Switzerland, pp. 73, 1998.

[12] Steenbergen, R.D.J.M. and Vrouwenvelder, A.C.W.M., Safety philosophy for existing structures and partial factors for traffic loads on bridges. Heron, 55(2), pp. 123-139, 2010.

[13] Sykora, M. and Holicky, M., Target reliability levels for the assessment of existing structures - case study. Proc. IALCCE 2012, eds. A. Strauss, K. Bergmeister and D.M. Frangopol, CRC Press/Balkema: Leiden, pp. 813820, 2012.

[14] Schueremans, L. and Van Gemert, D., Assessing the safety of existing structures: reliability based assessment framework, examples and application. Journal of Civil Engineering and Management, X(2), pp. 131141, 2004.

[15] Sykora, M. and Holicky, M., Reliability verification of industrial heritage buildings (submitted for publication). Engineering Mechanics, 2013.

[16] Ang, A.H.S. and Tang, W.H., Probabilistic Concepts in Engineering Emphasis on Applications to Civil and Environmental Engineering, John Wiley \& Sons: USA, pp. 420, 2007.

[17] Holicky, M., Reliability analysis for structural design, SUN MeDIA: Stellenbosch, pp. 199, 2009.

[18] Sankararaman, S. and Mahadevan, S., Likelihood-based representation of epistemic uncertainty due to sparse point data and/or interval data. Reliability Engineering \& System Safety, 96(7), pp. 814-824, 2011. 